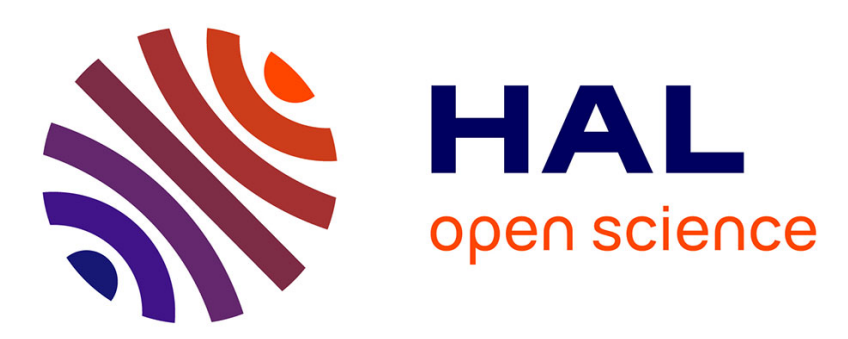

\title{
Exploring ripening of nanocapsules and emulsions in parenteral nutritional mixtures by experimental design
}

Y. Rahali, Patrick Saulnier, Jean-Pierre Benoit, Y. Bensouda

\section{To cite this version:}

Y. Rahali, Patrick Saulnier, Jean-Pierre Benoit, Y. Bensouda. Exploring ripening of nanocapsules and emulsions in parenteral nutritional mixtures by experimental design. Journal of Drug Delivery Science and Technology, 2013, 23 (3), pp.255-260. 10.1016/S1773-2247(13)50038-4 . hal-03179498

\section{HAL Id: hal-03179498 \\ https://univ-angers.hal.science/hal-03179498}

Submitted on 24 Mar 2021

HAL is a multi-disciplinary open access archive for the deposit and dissemination of scientific research documents, whether they are published or not. The documents may come from teaching and research institutions in France or abroad, or from public or private research centers.
L'archive ouverte pluridisciplinaire HAL, est destinée au dépôt et à la diffusion de documents scientifiques de niveau recherche, publiés ou non, émanant des établissements d'enseignement et de recherche français ou étrangers, des laboratoires publics ou privés. 


\title{
Exploring ripening of nanocapsules and emulsions in parenteral nutritional mixtures by experimental design
}

\author{
Y. Rahali ${ }^{1}$, P. Saulnier ${ }^{2}$, J.-P. Benoit ${ }^{2}$, Y. Bensouda ${ }^{1 *}$ \\ 'University Mohammed V Souissi of Rabat, Équipe de recherche en formulation et biopharmacie, \\ Faculté de Médecine et de Pharmacie, BP 6203, Rabat Instituts, Morocco \\ 'University of Angers, Inserm U1066, Micro et Nanomédecines biomimétiques \\ MINT, 4, rue Larrey, 49933 Angers Cedex 9, France \\ *Correspondence: y.bensouda@um5s.net.ma
}

\begin{abstract}
Lipid nanocapsules based on vegetal oils (vo-LNC) can be prepared and used to allow both the easy incorporation of oils in the aqueous phase and the stability of mixtures for parenteral nutrition. In this context of use, vo-LNC was shown an interesting process of ripening. To explore this ripening process, experimental design was used. The same mixture design was performed for both the incorporation of lipids by vo-LNC as by emulsion. The responses chosen for the experimental design was the average size and zeta potential of both. As expected, vo-LNC and emulsion were affected at different level by the ripening process. This indicates clearly that vo-LNC would permit the early incorporation of lipids in parenteral nutrition admixtures without any risk of instability and can be safely administered for parenteral use.
\end{abstract}

Key words: Lipid nanocapsules - Parenteral nutrition - Experimental design - Vegetal oils - Ripening.

In parenteral nutrition, lipid emulsions are usually presented separately from other nutrients [1-4]. The mixture of lipid emulsion with electrolytes, amino acids and glucose is made just before or during the administration since the stability of this mixture does not exceed $24 \mathrm{~h}[5,6]$.

Lipid nanocapsules based on vegetal oils (vo-LNC) can be prepared to be very stable nanometric devices for lipidic encapsulated components [7-11]. Their structure is a hybrid of polymeric nanocapsules and liposomes. Because of their oily core, which is surrounded by a tensioactive rigid membrane, they have a lipoprotein-like structure. These properties confer great stability to the structure [7, 12].

vo-LNC can be used to allow both the easy dispersion of the oily phases in water and an improvement of parenteral mixture stability [11]. Two oils are commonly used in parenteral nutrition: olive and soybean oils.

The preparation of vo-LNC with olive and soybean oil is possible thanks to the incorporation of Labrafac. The average size of vo-LNC in nutritional mixtures for parenteral administration is slightly and homogenously increased. The stability of vo-LNC is not influenced by the component of parenteral nutrition except a supposed steric increasing of average size after the ripening process during the first few days following mixture [11].

vo-LNC would permit the early incorporation of lipids in parenteral nutrition admixtures (PNA) without any risk of instability. Provided to adequately respond to solutol and Labrafac safety issues, different ranges of ready-mix adapted to different nutritional needs may be prepared in advance on a large scale without the risk of instability. The time-consuming step of preparing mixtures in hospitals could be completely avoided for the greater interest of both the patient and the pharmaceutical team [11].

Depending on the incorporation in different mixtures for parenteral nutrition, the size evaluation of vo-LNC based on the olive and soybean oils showed evidence of a ripening process. More precisely, it is the variation of size control coefficients of each component of parenteral nutrition after mixture which showed evidence of a ripening process [11].

In this work, we chose to explore this ripening process of vo-LNC by comparing the results of vo-LNC with those of the emulsion. This was possible by performing the same $\mathrm{D}$-optimal experimental design (mixture design) for both. For this experimental design, the responses considered are the size and the zeta potential.

We consider that the mathematical modeling and statistical analysis of selected responses over time (vo-LNC versus emulsion) will demonstrate the ripening process and will suggest the limits of use of vo-LNC in PNA.

The purpose is to show that vo-LNC resulting from this process of ripening display a long-term stability which allows safe administration for parenteral use.

\section{MATERIALS AND METHODS \\ 1. Materials}

Due to the complex composition of products, brand names will be used in this article. Lipoid S75-3 (soybean lecithin; $69 \%$ phosphatidylcholine) with an average molecular weight of 800 was a gift from Lipoïd GmbH (Ludwigshafen, Germany). Lipophilic Labrafac WL 1349 (capric and caprylic acid triglycerides) with an average molecular weight of $512 \mathrm{~g} \cdot \mathrm{mol}^{-1}$ and Solutol HS 15 (a mixture of free polyethylene glycol 660 and 12-hydroxystearate of polyethylene glycol 660) with an average molecular weight of $911 \mathrm{~g} . \mathrm{mol}^{-1}$ were kindly provided by Gattefossé SA (Saint-Priest, France) and BASF (Ludwigshafen, Germany), respectively. The water used was of an ultrapure grade from a Milli-Q plus system (Millipore, Paris, France). Olive oil was provided by the European Pharmacopoeia. Soybean oil was provided by Sigma-Aldrich. Amino acids $10 \%$ Baxter, glucose $50 \%$ B Braun, sodium chloride $20 \%$ Aguettant, potassium chloride $15 \%$ Biosedra, calcium $10 \%$ Aguettant, magnesium $1 \%$ Aguettant, monopotassium phosphate $13.6 \%$ Renaudin, emulsion for the infusion Oliclinomel N4-550E Baxter.

For the preparation of LNC, the materials used were: a stirring and heating plate (Ikamag RCT basic), a sensor for the precise control of temperature (Ikatron ETS-D4 fuzzy) and a conductivimeter (Consort C561, Fisher Bioblock Scientific). For the size control and zeta potential measurement of LNC and emulsion, a Zetasizer 3000HS (Malvern Instruments, France) was used. The software Design Expert was used for the experimental design and statistical tools. 


\section{Methods}

2.1. Preparation of lipid nanocapsules based on vegetal oils (vo-LNC)

LNC were prepared by a phase-inversion temperature method (PIT) $[7,10,12,13]$. The PIT method was first introduced by Shinoda and Saito (1969) and is now widely used in industry [7,13].

This low energy and solvent-free method uses the particular ability of emulsions stabilized by polyethoxylated nonionic surfactants to undergo a phase inversion following a variation of temperature. The transitional phase inversion occurs when, at a fixed composition, the relative affinity of the surfactant for the different phases is changed and controlled by the temperature. As a result, oil-in-water $(\mathrm{o} / \mathrm{w})$ macro-emulsion undergoes a phase inversion to a water-in-oil (w/o) one with increasing temperature, and vice versa [13].

Hence, the PIT method consists in a sudden break-up of such a microemulsion network by performing, at the PIT, rapid cooling and/ or a sudden water dilution. This stage is considered an irreversible process since it leads to the generation of the kinetically stable LNC. This great stability is due to the fact that the steric stabilization prevents droplet locculation and, therefore, coalescence $[7,10,13]$.

For the preparation of vo-LNC, the formula was olive oil $11.2 \%$, soybean oil $2.8 \%$, Labrafac $6 \%$, Solutol $25 \%$, Lipoïd $1,5 \%$ and water $53.5 \%$ [11].

The first step in forming the particles consisted of magnetic stirring of all the components while heating from ambient temperature to $85^{\circ} \mathrm{C}$ at a rate of $4{ }^{\circ} \mathrm{C} / \mathrm{min}$. Three cycles of progressive heating and cooling in between 85 and $60^{\circ} \mathrm{C}$ at a rate of $4^{\circ} \mathrm{C} / \mathrm{min}$ were carried out. The second step was a fast cooling-dilution process by cold water $(0 \pm$ $1{ }^{\circ} \mathrm{C}$ ) in order to divide the hot initial structure. Then, slight magnetic stirring was applied to the nanocapsule suspension for $5 \mathrm{~min}$ [8].

The average size, polydispersity index and zeta potential of the nanocarriers were determined by the Zetasizer 3000HS (Malvern Instruments, France). Zeta potential measurements were made at constant conductivity.

\subsection{Evaluation of vo-LNC and emulsion behavior in PNA by experimental design}

To evaluate the vo-LNC and emulsion behavior in PNA, we should perform experiments in the whole experimental domain, which represents an infinite number of formula; therefore, a tool which allows us to collect the same information with less experiments was used [14]. In this article, a D-optimal experimental design (mixture design) was selected to evaluate and model the effects of parenteral nutrition compounds on the size and zeta potential of vo-LNC and emulsion. This provides maximum information from a limited number of experiments. Moreover, when all the results are expressed as models, it is possible to determine, mathematically or graphically, a composition satisfying the required criteria $[11,15]$. The previous chosen formula of LNC based on olive and soybean oil was used following classical lipid amounts used in parenteral nutrition. To make this experimental design, the lower and upper limits of nutritional components were fixed (Table I). The software Design Expert permits the matrix of 16 formulations at different ratios of all five components (Table II). With size and zeta potential measurements, it enables the calculation for mixture designs and drawing graphs for design evaluation. It

Table I - Lower and upper limits of nutritional components used to made experimental design.

\begin{tabular}{|l|c|c|}
\hline Nutritional constituent & Lower limit (\%) & Upper limit (\%) \\
\hline Amino acids & 2 & 4 \\
Glucose & 8 & 12 \\
Lipids (prepared vo-LNC) & 2.8 & 5.6 \\
Electrolytes & 0.5 & 0.7 \\
Water & 78 & 87 \\
\hline
\end{tabular}

can handle many models of experimental design such as factorial or mixture design $[11,15]$.

Olive and soybean oils are usually used at 80:20 ratio in parenteral nutrition. This ratio has been integrated in place of the percentage of vegetal oil. Experimental design was adjusted including: oils in LNC or emulsion depending on the case, electrolyte mixture, amino acids mixture or glucose and water. The lower and upper limits of nutritional components used in experimental design are shown in Table I. These limits were determined according to general nutritional indications $[1,2,16-20]$.

The measured responses are size and zeta potential of vo-LNC and emulsion at D0, D1, D2, D3, D4, D7, D14 and D28 (Table II).

Size is an obvious criterion of control of dispersions, and zeta potential is an important and useful indicator of particle surface charge which can be used to predict and control the stability of dispersions. The measurement of zeta potential is often the key to understanding dispersion and aggregation processes in applications $[7,21]$.

\subsection{Statistical analysis}

The software Design Expert is a statistical tool that permits calculation for factorial designs and drawing graphs for design evaluation. It can handle many models of experimental design such as factorial or mixture design [15]. The statistical analysis of variance, the RSquared, the precision and mathematical modeling of the responses by polynomial equations at D0, D1, D2, D3, D4, D7, D14 and D28 was carried out by Design Expert $[11,15]$.

The purpose of the statistical analysis was to confirm the validity of the mathematical modeling.

\section{RESULTS AND DISCUSSION \\ 1. Evaluation of vo-LNC and emulsion behavior in PNA by experimental design}

Mixtures were designed by Design Expert to explore the behavior of vo-LNC and emulsion in PNA. The formulas of the 16 mixtures with the selected responses of experimental design are shown in Table II. The values of measured responses are shown to have good result quality by Malvern Dispersion Technologie Software 5.10.

The average size of vo-LNC before mixture is $49 \mathrm{~nm}$, becoming $60 \mathrm{~nm}$ ( $22.4 \%$ increase) after mixture in the worst case for runs 3 , 4 and 9 at day 4 (Table II). In the previously studied vo-LNC [11], this variation is close to $50 \%$. This decrease is correlated to a better mastery of process preparation. The average size of emulsion before mixture is $276 \mathrm{~nm}$, becoming $465 \mathrm{~nm}$ (68\% increase) after mixture in the worst case for run 3 at day 4 (Table II).

The standard deviation of size expressed as a percentage for voLNC is at most $5 \%$. For the emulsion, it fluctuates around $12 \%$ and increases to $16 \%$ at day 14 and to $17 \%$ at day 28 (Table In).

Phase separation has affected emulsions from D1 to cover all mixtures except 11 and 12 (Table II).

With regard to zeta potentials, it is currently admitted that a value under $|30| \mathrm{mV}$, optimum $>|60| \mathrm{mV}$, is required for full electrostatic stabilization; potentials between $|5|$ and $|15| \mathrm{mV}$ are in the region of limited flocculation; and between $|5|$ and $|3| \mathrm{mV}$ of maximum flocculation [21].

The average zeta potential of vo-LNC and emulsion are under $131 \mathrm{mV}$ (Table II). In most cases, the measured zeta potentials indicated that all mixtures are at maximum flocculation level. For vo-LNC, the small variability of size in the maximum condition of flocculation indicates the great stability of this lipid dispersion in nutritional mixtures. In contrast, for emulsion, the large variability of size indicates, as expected, the instability of this kind of dispersion. The great stability of vo-LNC is due to the fact that the steric stabilization prevents the droplets' flocculation and, therefore, coalescence.

However, the standard deviation of zeta potential, expressed as a percentage, for vo-LNC is more or less stable and for emulsion is 


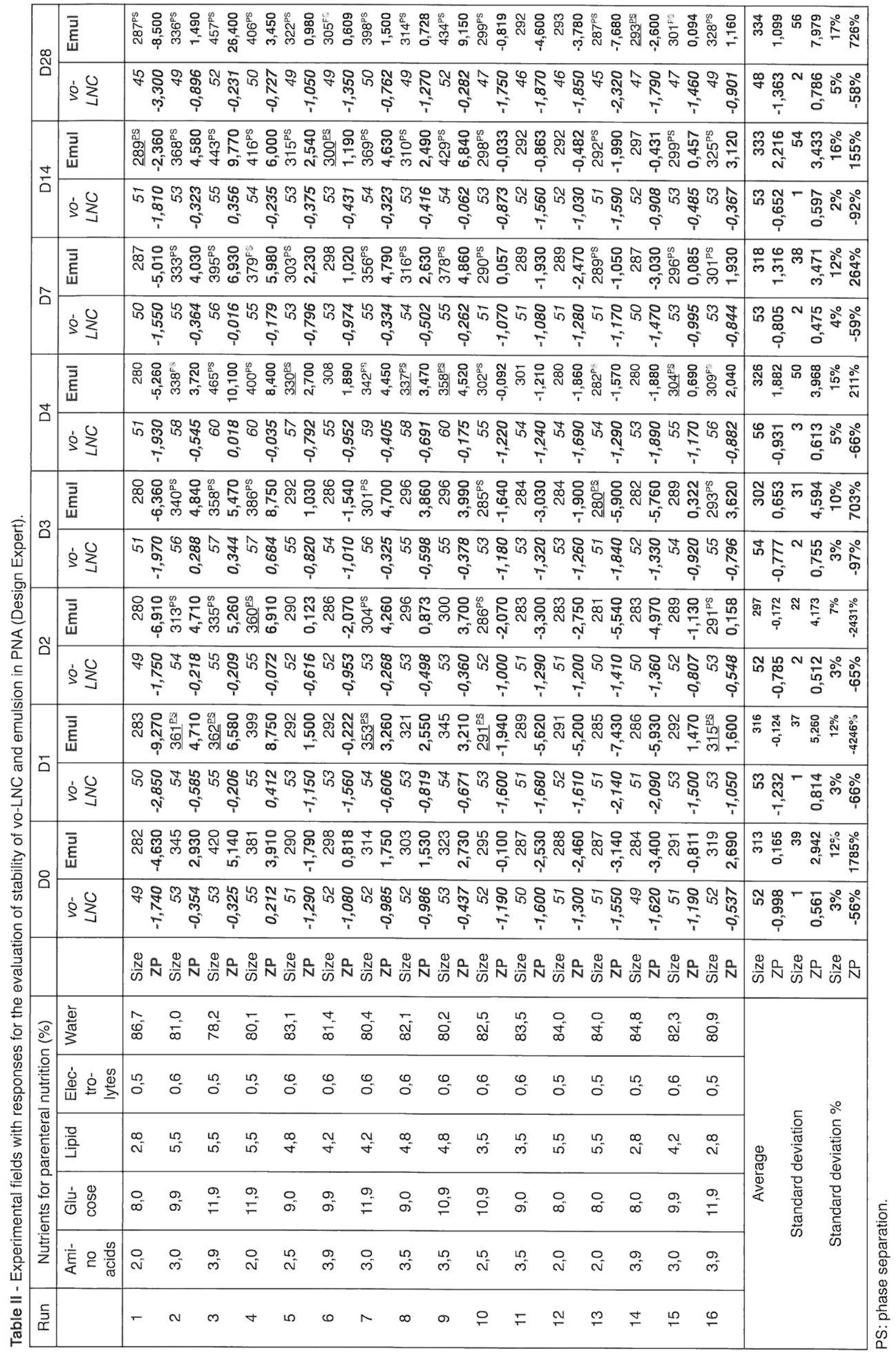


very instable (Table II). This is consistent with the slight variation in size of vo-LNC and the wide variation in size of the emulsion.

Considering the five parameters, the experimental design could not show a general graphical representation of results. However, equations are obtained for each case.

The response of average size and zeta potential of LNC and the emulsion in PNA at day 0,1,2, 3, 4, 7, 14 and 28 was expressed by a linear equation with X1: Amino acids, X2: Glucose, X3: Lipids (LNC), X4: Electrolytes and X5: Water.

\section{- LNC size equations:}

$\mathrm{LNC}$ size $_{\mathrm{D} 0}=0.44 \mathrm{X} 1+1.11 \mathrm{X} 2+1.12 \mathrm{X} 3+1.20 \mathrm{X} 4+0.41 \mathrm{X} 5$

$\mathrm{LNC}$ size $_{\mathrm{D} 1}=0.68 \mathrm{X} 1+1.07 \mathrm{X} 2+1.08 \mathrm{X} 3+3.68 \mathrm{X} 4+0.41 \mathrm{X} 5$

$\mathrm{LNC}_{\text {size }}=0.75 \mathrm{X} 1+1.18 \mathrm{X} 2+1.22 \times 3+0.55 \mathrm{X} 4+0.40 \mathrm{X} 5$

$\mathrm{LNC}_{\text {size }}{ }_{\mathrm{D} 3}=1.09 \mathrm{X} 1+1.14 \mathrm{X} 2+1.23 \mathrm{X} 3+4.67 \mathrm{X} 4+0.38 \mathrm{X} 5$

$\mathrm{LNC}_{\mathrm{Nize}}=1.16 \mathrm{X} 1+1.42 \mathrm{X} 2+1.90 \times 3+6.06 \mathrm{X} 4+0.33 \times 5$

$\mathrm{LNC}_{\text {size }} \mathrm{D}_{\mathrm{D}}=0.97 \mathrm{X} 1+1.12 \mathrm{X} 2+1.35 \mathrm{X} 3+5.38 \mathrm{X} 4+0.37 \mathrm{X} 5$

$\mathrm{LNC}_{\text {size }}{ }_{\mathrm{D} 14}=0.95 \mathrm{X} 1+0.88 . \mathrm{X} 2+0.87 \mathrm{X} 3+2.00 \mathrm{X} 4+0.44 \mathrm{X} 5$

$\mathrm{LNC}_{\text {size }}{ }_{\mathrm{D} 28}=1.49 \mathrm{X} 1+1.18 \mathrm{X} 2+1.32 \mathrm{X} 3+1.82 \mathrm{X} 4+0.31 \mathrm{X} 5$

- Emulsion size equations:

Emulsion size $e_{D 0}=13.63 X 1+17.36 \times 2+20.43 \times 3-249.82 \times 4+1.83 \times 5$

Emulsion size $_{\mathrm{DI}}=2.26 \mathrm{X} 1+17.87 \mathrm{X} 2+17.00 \mathrm{X} 3-100.50 \mathrm{X} 4+1.39 \mathrm{X} 5$

Emulsion size $_{\mathrm{D} 2}=1.18 \mathrm{X} 1+11.60 \mathrm{X} 2+11.67 \mathrm{X} 3-100.16 \times 4+2.24 \mathrm{X} 5$

Emulsion size $_{D 3}=1.96 \mathrm{X} 1+13.90 \times 2+16.68 \times 3-162.12 \times 4+2.15 \times 5$

Emulsion size $_{\mathrm{D} 4}=16.77 \mathrm{X} 1+19.17 \mathrm{X} 2+25.94 \mathrm{X} 3-112.47 \mathrm{X} 4+0.43 \mathrm{X} 5$

Emulsion size $_{\mathrm{D} 7}=8.77 \mathrm{X} 1+16.61 \mathrm{X} 2+19.28 \mathrm{X} 3-76.23 \mathrm{X} 4+1.04 \mathrm{X} 5$

Emulsion size $_{D 14}=12.65 \mathrm{X} 1+22.95 \mathrm{X} 2+24.86 \mathrm{X} 3-153.10 \mathrm{X} 4+0.55 \times 5$

Emulsion size $_{\mathrm{D} 28}=13.46 \mathrm{X} 1+25.07 \mathrm{X} 2+22.60 \mathrm{X} 3-130.05 \mathrm{X} 4+0.24 \mathrm{X} 5$

- LNC zeta potential equations:

LNC zeta potential $_{\mathrm{D} 0}=0.04 \mathrm{X} 1+0.23 \mathrm{X} 2+0.20 \times 3-1.53 \mathrm{X} 4-0.04 \mathrm{X} 5$

$\mathrm{LNC}_{\text {zeta potential }}{ }_{\mathrm{D} 1}=0.07 \mathrm{X} 1+0.28 \mathrm{X} 2+0.35 \mathrm{X} 3+0.51 \mathrm{X} 4-0.07 \mathrm{X} 5$

LNC zeta potential $_{D 2}=0.06 \mathrm{X} 1+0.18 \times 2+0.19 \times 3+1.20 \times 4-0.05 \times 5$

$\mathrm{LNC}_{\text {zeta potential }}{ }_{\mathrm{D} 3}=0.12 \mathrm{X} 1+0.25 \mathrm{X} 2+0.32 \mathrm{X} 3-0.24 \mathrm{X} 4-0.06 \mathrm{X} 5$

LNC zeta potential ${ }_{\mathrm{D} 4}=0.08 \mathrm{X} 1+0.21 \mathrm{X} 2+0.26 \mathrm{X} 3+1.43 \mathrm{X} 4-0.06 \mathrm{X} 5$

LNC zeta potential $_{\mathrm{D} 7}=0.08 \mathrm{X} 1+0.15 \mathrm{X} 2+0.22 \times 3+0.93 \mathrm{X} 4-0.05 \mathrm{X} 5$

LNC zeta potential $_{\mathrm{D} 14}=0.42 \mathrm{X} 1+0.48 \mathrm{X} 2+0.53 \mathrm{X} 3+0.58 \mathrm{X} 4+0.63 \mathrm{X} 5$

$\mathrm{LNC}_{\text {zeta potential }}{ }_{\mathrm{D} 28}=0.37 \mathrm{X} 1+0.21 \mathrm{X} 2+0.30 \mathrm{X} 3+1.52 \mathrm{X} 4-0.08 \mathrm{X} 5$

- Emulsion zeta potential equations:

Emulsion zeta potential $_{\mathrm{DO}}=0.96 \mathrm{X} 1+1.20 \mathrm{X} 2+1.01 \mathrm{X} 3-1.98 \mathrm{X} 4-0.22 \times 5$

Emulsion zeta potential $_{D 1}=0.71 \mathrm{X} 1+1.96 \mathrm{X} 2+1.90 \mathrm{X} 3+11.46 \mathrm{X} 4-0.44 \mathrm{X} 5$

Emulsion zeta potential $_{\mathrm{D} 2}=0.24 \mathrm{X} 1+1.59 \mathrm{X} 2+1.69 \mathrm{X} 3+5.67 \mathrm{X} 4-0.33 \mathrm{X} 5$

Emulsion zeta potential ${ }_{D 3}=0.14 \mathrm{X} 1+1.84 \mathrm{X} 2+1.55 \mathrm{X} 3+6.47 \mathrm{X} 4-0.35 \mathrm{X} 5$

Emulsion zeta potential $_{\mathrm{D} 4}=1.21 \mathrm{X} 1+1.39 \mathrm{X} 2+1.93 \mathrm{X} 3-2.05 \mathrm{X} 4-0.28 \mathrm{X} 5$

Emulsion zeta potential $_{\mathrm{D} 7}=0.67 \mathrm{X} 1+1.28 \mathrm{X} 2+1.56 \mathrm{X} 3+5.04 \mathrm{X} 4-0.28 \mathrm{X} 5$

Emulsion zeta potential $_{14}=1.31 \mathrm{X} 1+1.21 \mathrm{X} 2+1.47 \mathrm{X} 3-4.53 \mathrm{X} 4-0.21 \mathrm{X} 5$

Emulsion zeta potential $_{\text {D28 }}=4.85 \mathrm{X} 1+1.98 \mathrm{X} 2+3.34 \mathrm{X} 3-18.78 \mathrm{X} 4-0.45 \mathrm{X} 5$

These equations predict the size and zeta potential of vo-LNC and the emulsion in the experimental domain. Also the variation of size and zeta potential control coefficient during the 28 days after mixture for both vo-LNC and emulsion indicate the stability of the dispersion. For both vo-LNC and emulsion, a variation of size and zeta potential control coefficients of each parameter during the 28 days after mixture with parenteral nutrition component shorvs an interesting ripening process. The electrolytes show the most important fluctuant influence on the size (Figure 1) and zeta potential (Figure 2).

Size electrolyte coefficient fluctuate between 0.5 to 6 for vo-LNC and between -250 to -76 for emulsion (Figure 1). Zeta potential electrolyte coefficients fluctuate between -1.5 to 1.5 for vo-LNC and between -19 to 11.5 (Figure 2).

The ripening process affects the vo-LNC in a very limited way compared to the emulsion, as it can be demonstrated by the small

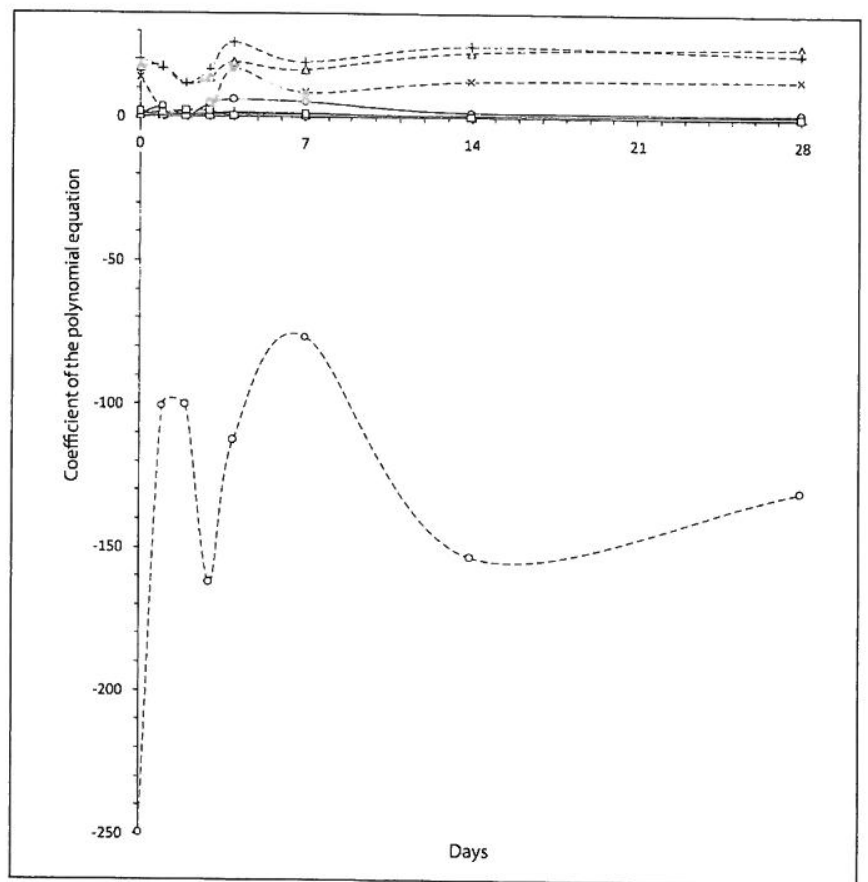

Figure 1 - Variation of size control coefficients of each parameters during the 28 days after mixture of vo-LNC (-) and emulsion (--). X: amino acids, $\Delta$ : glucose, +: lipids (vo-LNC), O: electrolytes and $\square$ : water fractions.

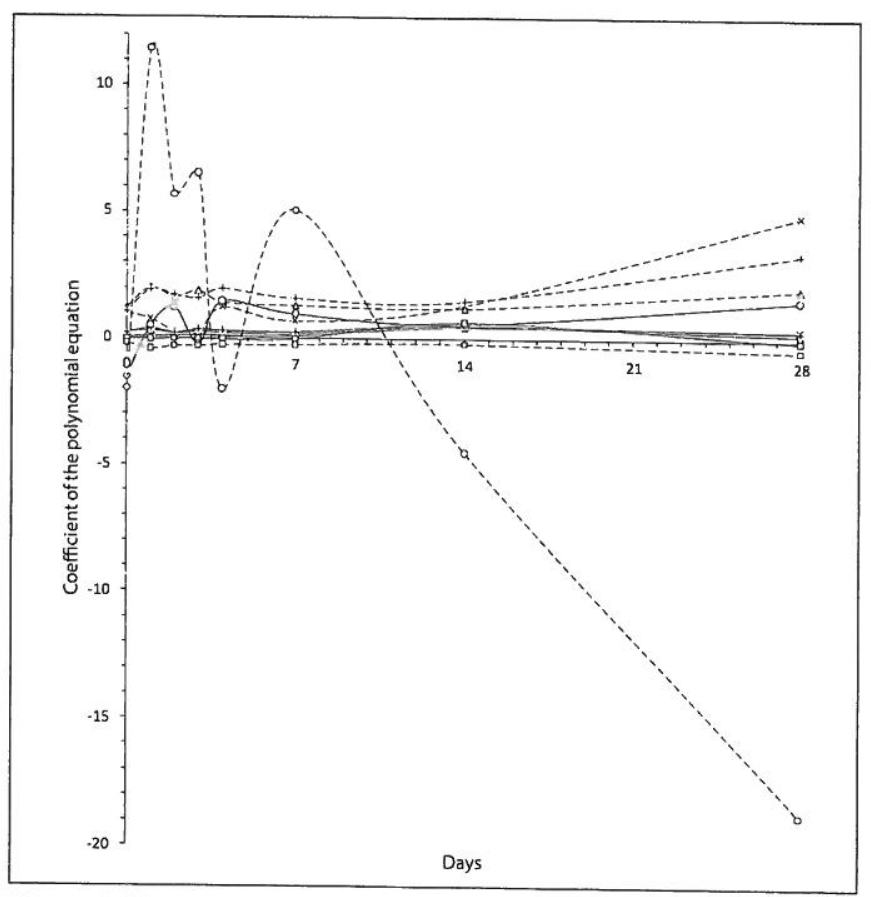

Figure 2-Variation of size control coefficients of each parameters during the 28 days after mixture of vo-LNC $(-)$ and emulsion $(--)$. X: amino acids, $\Delta$ : glucose, + : lipids (vo-LNC), O: electrolytes and $\square$ : water fractions.

fluctuations of the size and zeta potential coefficients of the components between the different days. This is clearly consistent with the analysis of size and zeta potential responses shown on Table II.

Ostwald ripening is clearly affecting the emulsion with a large size increase [22-25]; in contrast, the small size increase of vo-LNC cannot be interpreted as classical Ostwald ripening or coalescence [26]. This is related to the tensioactive rigid membrane with a lipoprotein-like structure [7]. The stability of vo-LNC after D28 can be expected by considering the stability of the coefficients of modeling equations between D14 and D28. 


\section{Statistical analysis}

Table III shows the significance of results and mathematical model used. All the F values of the models beyond 5.81 imply that the models are significant. Values under $0.05 \%$ were considered statistically significant. The R-squared beyond 0.67 is in reasonable agreement. Precision measurements of the signal to-noise ratio should be greater than 4: our ratios are beyond 7.40.

The significance of the statistical analysis at D0, D1, D2, D3, D4, D7, D14 and D28 shows that the responses of size and zeta potential of mixed vo-LNC and emulsion in PNA are modeled successfully. However, this indicates that if the colloidal structures have been contaminated, statistical analysis could not be significant and the signal will be disturbed by noises.

Exploring vo-LNC and emulsion in PNA by experimental design shows that, as expected, emulsion are highly affected by Ostwald ripening process. After mixture with parenteral nutrition component, emulsion shows a high increase in size, high fluctuation of zeta potential and is widely affected by the phase separation. This is why it cannot be administered safely for parenteral use after $24 \mathrm{~h}$. In contrast, vo-LNC show very low fluctuations of size and zeta potential; this confirms the great stability in the same conditions of mixture with parenteral nutrition component.

In the case of emulsion, electrolytes led to the destabilization of the system, while in the case of vo-LNC, they compete with the steric effect which prevents the droplets' flocculation and, therefore, coalescence.
The small impact of the ripening process on the size of vo-LNC suggests that it can be administered safely after 28 days for parenteral use. This can be supposed by considering the stability of the coefficients of modeling equations between D14 and D28.

\section{REFERENCES}

1. Carpentier Y.A. - Basic in clinical nutrition: substrates used in parenteral and enteral nutrition - lipids. - e-SPEN, the European e-Journal of Clinical Nutrition and Metabolism, 4 (2), e66-e68, 2009.

2. Pertkiewicz M., Szczygiel B., Sobotka L., Dudrick S.J. - Basics in clinical nutrition: composition of nutritional admixtures and formulas for parenteral nutrition. - e-SPEN, the European eJournal of Clinical Nutrition and Metabolism, 4 (4), e161-e163, 2009.

3. Barnett M.I., Pertkiewicz M., Cosslett A.G., Mühlebach S. Basics in clinical nutrition: parenteral nutrition admixtures, how to prepare parenteral nutrition (PN) admixtures. - e-SPEN, the European e-Journal of Clinical Nutrition and Metabolism, 4 (3), e114-e116, 2009.

4. Pertkiewicz M., Dudrick S.J. - Basics in clinical nutrition: Parenteral nutrition, ways of delivering parenteral nutrition and peripheral parenteral nutrition (PPN). - e-SPEN, the European e-Journal of Clinical Nutrition and Metabolism, 4 (3), e125-e127, 2009.

5. Pertkiewicz M., CosslettA., Mühlebach S., Dudrick S.J. - Basics in clinical nutrition: stability of parenteral nutrition admixtures. - e-SPEN, the European e-Journal of Clinical Nutrition and Metabolism, 4 (3), e117-e119, 2009.

6. Chambrier C., Lauverjat M., Boulétreau P. -Émulsions lipidiques :

Table III - Significance of the results and mathematical model used.

\begin{tabular}{|c|c|c|c|c|c|c|c|c|}
\hline & & & Model & $\mathrm{F}_{0.05}$ & $p$ value & $\begin{array}{c}\text { Significance for alpha } \\
\text { at } 5 \% \\
\end{array}$ & $\begin{array}{c}\text { R-squared } \\
\left(\mathrm{R}^{2}\right)\end{array}$ & Precision \\
\hline \multirow[t]{4}{*}{ DO } & vo-LNC & Size & Linear & 23.32 & $<0.0001$ & Significant & 0.89 & 15.47 \\
\hline & & $\mathrm{ZP}$ & Linear & 12.11 & 0.0005 & Significant & 0.81 & 11.66 \\
\hline & Emul & Size & Linear & 12.05 & 0.0005 & Significant & 0.81 & 12.23 \\
\hline & & $\mathrm{ZP}$ & Linear & 35.77 & $<0.0001$ & Significant & 0.93 & 21.72 \\
\hline \multirow[t]{4}{*}{ D1 } & vo-LNC & Size & Linear & 22.48 & $<0.0001$ & Significant & 0.89 & 16.15 \\
\hline & & ZP & Linear & 14.97 & 0.0002 & Significant & 0.84 & 13.52 \\
\hline & Emul & Size & Linear & 7.80 & 0.0031 & Significant & 0.73 & 8.88 \\
\hline & & ZP & Linear & 14.59 & 0.0002 & Significant & 0.84 & 13.11 \\
\hline \multirow[t]{4}{*}{ D2 } & vo-LNC & Size & Linear & 15.35 & 0.0002 & Significant & 0.84 & 13.72 \\
\hline & & ZP & Linear & 15.61 & 0.0002 & Significant & 0.85 & 13.66 \\
\hline & Emul & Size & Linear & 7.00 & 0.0047 & Significant & 0.72 & 8.39 \\
\hline & & ZP & Linear & 15.95 & 0.0002 & Significant & 0.85 & 13.48 \\
\hline \multirow[t]{4}{*}{ D3 } & vo-LNC & Size & Linear & 12.06 & 0.0005 & Significant & 0.81 & 12.70 \\
\hline & & ZP & Linear & 9.70 & 0.0013 & Significant & 0.78 & 11.26 \\
\hline & Emul & Size & Linear & 5.81 & 0.0092 & Significant & 0.67 & 7.40 \\
\hline & & ZP & Linear & 11.45 & 0.0007 & Significant & 0.80 & 11.05 \\
\hline \multirow[t]{4}{*}{ D4 } & vo-LNC & Size & Linear & 17.41 & 0.0001 & Significant & 0.86 & 15.22 \\
\hline & & ZP & Linear & 25.12 & $<0.0001$ & Significant & 0.90 & 17.50 \\
\hline & Emul & Size & Linear & 7.77 & 0.0032 & Significant & 0.74 & 10.50 \\
\hline & & $\mathrm{ZP}$ & Linear & 24.02 & $<0.0001$ & Significant & 0.90 & 18.49 \\
\hline \multirow[t]{4}{*}{ D7 } & vo-LNC & Size & Linear & 17.87 & $<0.0001$ & Significant & 0.86 & 15.32 \\
\hline & & ZP & Linear & 20.66 & $<0.0001$ & Significant & 0.88 & 16.35 \\
\hline & Emul & Size & Linear & 7.60 & 0.0034 & Significant & 0.73 & 9.81 \\
\hline & & $\mathrm{ZP}$ & Linear & 32.50 & $<0.0001$ & Significant & 0.92 & 20.40 \\
\hline \multirow[t]{4}{*}{ D14 } & vo-LNC & Size & Linear & 11.43 & 0.0007 & Significant & 0.80 & 12.50 \\
\hline & & $\mathrm{ZP}$ & Linear & 11.25 & 0.0007 & Significant & 0.80 & 12.98 \\
\hline & Emul & Size & Linear & 7.39 & 0.0038 & Significant & 0.73 & 9.66 \\
\hline & & $\mathrm{ZP}$ & Linear & 14.71 & 0.0002 & Significant & 0.84 & 14.66 \\
\hline \multirow[t]{4}{*}{ D28 } & vo-LNC & Size & Linear & 13.12 & 0.0004 & Significant & 0.83 & 13.91 \\
\hline & & $\mathrm{ZP}$ & Linear & 21.08 & $<0.0001$ & Significant & 0.88 & 17.64 \\
\hline & Emul & Size & Linear & 7.40 & 0.0038 & Significant & 0.73 & 9.55 \\
\hline & & ZP & Linear & 7.53 & 0.0036 & Significant & 0.73 & 11.16 \\
\hline
\end{tabular}

$F_{0.05}$ : Fisher's exact test for alpha at $5 \%$. 
indication des différentes émulsions lipidiques. - Nutr. Clin. Metab., 20 (2), 73-78, 2006.

7. Huynh N.T., Passirani C., Saulnier P., Benoit J.P. - Lipid nanocapsules: A new platform for nanomedicine. - Int. J. Pharm. 379 (2), 201-209, 2009.

8. Heurtault B., Saulnier P., Pech B., Benoît J.P., Proust J.E. Interfacial stability of lipid nanocapsules. - Colloid Surface B. 30 (3), 225-235, 2003.

9. Acosta E. - Bioavailability of nanoparticles in nutrient and nutraceutical delivery. - Curr. Opin. Colloid In., 14 (1), 3-15, 2009.

10. Anton N., Benoit J.-P., Saulnier P. - Design and production of nanoparticles formulated from nano-emulsion templates--A review. - J. Control. Release, 128 (3), 185-199, 2008.

11. Rahali Y., Saulnier P., Benoit J.P., Bensouda Y. - Incorporating vegetal oils in parenteral nutrition using lipid nanocapsules. - J. Drug Del. Sci. Tech., 20 (6), 425-429, 2010.

12. Babu Dhanikula A., Mohamed Khalid N., Lee S.D., Yeung R., Risovic V., Wasan K.M., Leroux J.-C. - Long circulating lipid nanocapsules for drug detoxification. - Biomaterials, 28 (6), 1248-1257, 2007.

13. Anton N., Gayet P., Benoit J.-P., Saulnier P. - Nano-emulsions and nanocapsules by the PIT method: an investigation on the role of the temperature cycling on the emulsion phase inversion. - Int. J. Pharm., 344 (1-2), 44-52, 2007.

14. Claeys-Bruno M., Lamant J., Blasco L., Phan-Tan-Luu R., Sergent M. - Development of a skin care formulation using experimental designs. - Chemometr. Intell. Lab., 96 (2), 101 107, 2009.

15. Rahali Y., Pensé-Lhéritier A.-M., Mielcarek C., Bensouda Y. - Optimization of preservatives in a topical formulation using experimental design. - Int. J. Cosmetic Sci., 31 (6), 451-460, 2009.

16. Koletzko B. - Basic concepts in nutrition: Nutritional needs of children and adolescents. - e-SPEN, the European e-Journal of Clinical Nutrition and Metabolism, 3 (4), e179-e184, 2008.

17. Carpentier Y.A. - Basic in clinical nutrition: substrates used in parenteral and enteral nutrition-carbohydrates. - e-SPEN, the European e-Journal of Clinical Nutrition and Metabolism, 4 (2) e57-e58, 2009.
18. Fürst $P$. - Basics in clinical nutrition: special substrates for parenteral nutrition. - e-SPEN, the European e-Journal of Clinical Nutrition and Metabolism, 4 (2), e53-e54, 2009.

19. Carpentier Y.A. - Basics in clinical nutrition: Substrates used in parenteral and enteral nutrition - Energy. - e-SPEN, the European e-Journal of Clinical Nutrition and Metabolism, 4 (2), e55-e56, 2009.

20. Tappy L., Berger M.M., Schwarz J.-M., Schneiter P., Kim S., Revelly J.-P., Chioléro R. - Metabolic effects of parenteral nutrition enriched with n-3 polyunsaturated fatty acids in critically ill patients. - Clin. Nutr., 25 (4), 588-595, 2006

21. Heurtault B., Saulnier P., Pech B., Proust J.-E., Benoit J.-P. - Physico-chemical stability of colloidal lipid particles. - Biomaterials, 24 (23), 4283-4300, 2003.

22. Liu W., Sun D., Li C., Liu Q., Xu J. - Formation and stability of paraffin oil-in-water nano-emulsions prepared by the emulsion inversion point method. - J. Colloid Interface Sci., 303 (2), 557 563, 2006.

23. Al-Edresi S., Baie S. - Formulation and stability of whitening VCO-in-water nano-cream. - Int. J. Pharm., 373 (1-2), 174-178, 2009.

24. Izquierdo P., Feng J., Esquena J., Tadros T.F., Dederen J.C., Garcia M.J., Azemar N., Solans C. - The influence of surfactant mixing ratio on nano-emulsion formation by the pit method. - J. Colloid Interface Sci., 285 (1), 388-394, 2005.

25. Yang H.J., Cho W.G., Park S.N. - Stability of oil-in-water nanoemulsions prepared using the phase inversion composition method. - J. Ind. Eng. Chem., 15 (3), 331-335, 2009.

26. Perrier T., Saulnier P., Fouchet F., Lautram N., Benoît J.-P. - Postinsertion into Lipid NanoCapsules (LNCs): from experimental aspects to mechanisms. - Int. J. Pharm., 396 (1-2), 204-209, 2010.

\section{MANUSCRIPT}

Received 7 July 2012, accepted for publication 20 November 2012. 